\title{
ANALISIS PENGARUH CUSTOMER EXPERIENCE TERHADAP MINAT BELI ULANG KONSUMEN PADA DRESS UP LAUNDRY \& DRY CLEANING SERVICE CABANG BENHIL JAKARTA PUSAT
}

\author{
Agus Wahyono \\ Program Studi Manajemen Universitas Satya Negara Indonesia \\ agoeswahyono9@gmail.com
}

\begin{abstract}
The purpose of this research is to know the influence of Customer Experience against the interests of consumers on the anniversary of buy Dress Up Laundry \& Dry Cleaning Service data collected using the formula slovin with spread 100 respondents customer Dress Up Laundry Dry Cleaning Service \& methodology this research is quantitative analysis performed with the associative analysis of multiple linear regression. The results showed partially sense experience is a positive and significant effect against the interest to buy, feel the experience positive and significant effect against the interest to buy, think positive and influential experience significantly to buy interest, act experience positive and significant effect against the interest to buy, relate the experience positive and significant effect against interest buy. simultaneous sense, feel, think, act, relate together in the same positive and significant effect of $75.3 \%$ and the remaining $24.7 \%$ influenced by other variables that are not described in This research.
\end{abstract}

Keywords: sense experience, feel, experience, think experience act experience, relate the experience

\section{PENDAHULUAN}

Pada zaman modern sekarang ini, usaha laundry menunjukkan perkembangan yang sangat signifikan. Perkembangan bisnis laundry ditandai dengan banyak laundry yang bermunculan dengan aneka jasa cuci pakaian. Semakin banyaknya laundry yang berdiri, maka semakin kuat persaingan yang dihadapi laundry. Untuk menghadapi persaingan tersebut, pemilik laundry dituntut untuk selalu peka terhadap perubahan-perubahan yang terjadi pada pasar dan mampu menciptakan inovasi yang kreatif serta mengadakan promosi agar jasa yang ditawarkan menarik konsumen sehingga laundry tersebut dapat bertahan dan berkembang pesat.

Perkembangan Laundry di Indonesia masih sangat menjanjikan. Pada jaman sekarang perubahan gaya hidup masyarakat yang tinggi serba praktis dan instan membuat laundry merupakan suatu kebutuhan orang dalam hal mencuci pakaian. Besarnya pangsa pasar laundry di Indonesia atas kebutuhan jasa laundry yang terus meningkat membuat dress up mengambil peluang. Dress Up Laundry \& Dry Cleaning Service terus berkeinginan membuka outletnya hingga keseluruh wilayah Indonesia. Di seluruh Indonesia pertumbuhan jasa Laundry dapat ditujukkan dengan perolehan omset pada angka 6 Triliun dan pertumbuhan jasa Laundry di Dki Jakarta adalah menurut Ketua Umum Asosiasi Profesi Laundry Indonesia (APLI) Wasono Raharjo mengatakan setidaknya terdapat 4 sektor Laundry yang cukup besar. Pertama, Laundry hotel yang bertumbuh sangat luar biasa dalam 5 hingga 10 tahun terakhir seiring dengan pertambahan jumlah hotel yang kian pesat hingga mencapai 1.778 yang memakai jasa Laundry. Dan omset yang diperoleh dari jasa Laundry hotel dijabodetabek saja untuk perhitungan kasarnya bisa mencapai Rp200 miliar hingga Rp250 miliar setiap harinya. Kedua, Laundry Rumah sakit yang jaminan kebersihannya harus lebih terjaga dan pencuciannya dilakukan setiap hari. Dari laundry rumah sakit omset yang diperoleh bervariatif dengan perkiraan sekitar Rp246,7 miliar. 
Ketiga, Laundry komersil yang mulai menggeliat dalam 20 tahun terakhir. Ada yang berupa Laundry satuan atau Laundry kiloan. Jumlahnya dijabodetabek mencapai sekitar 24.180 pelaku usaha.

Keempat, Laundry garmen yang jumlahnya mencapai sekitar 23.600 pelaku usaha, (SWA,2016).Di Jakarta persaingan Laundry komersil cukup signifikan jumlahnya, dibawah ini disajikan beberapa data Laundry komersil yang cukup dikenal dan memiliki citra image sebagai Laundry Action Experience.

Tabel 1.1

Nama-nama Laundry Di Jakarta

\begin{tabular}{|l|l|}
\hline NamaLaundry & Jumlah Outlet \\
\hline Laundrette & 65 \\
\hline Dress Up & 20 \\
\hline Jeeves Of Belgravia & 8 \\
\hline De Wasz & 7 \\
\hline Super Wash & 2 \\
\hline
\end{tabular}

Sumber: Data diolahpenulis, 2017

Berdasarkan Tabel 1.1 dapat disimpulkan Laundrette Laundry merupakan pesaing Dress Up Laundry karena Laundrette Laundry mempunyai 65 outlet di Jakarta. Laundrette Laundry sudah mempunyai reputasi atau pengalaman dalam mengelola usaha jasa Laundry dari 1996. Oleh karena itu agar dapat bersaing Dress Up Laundry perlu meningkatkan Customer Experience agar customer tidak beralih kepesaing. Berikut ini adalah segmentasi pengguna jasa laundry di Jakarta

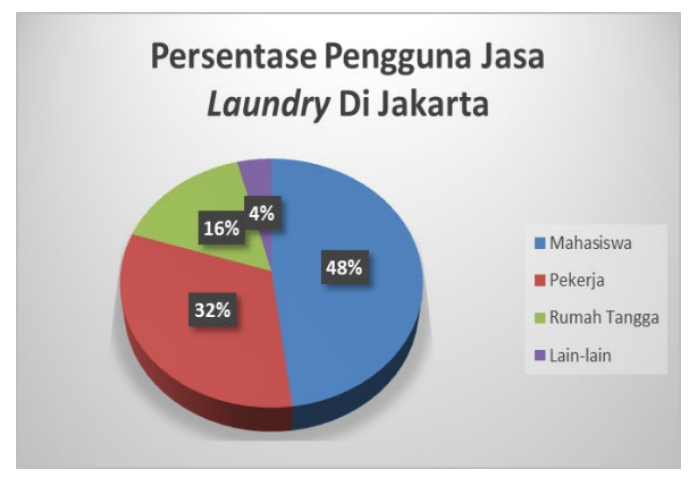

Gambar 1.1

Segmentasi Pengguna Laundry Di Jakarta

Sumber: SWA (2016)

Berdasarkan gambar 1.1 dapat disimpulkan bahwa pengguna jasa Laundry mayoritas adalah mahasiswa sebesar $48 \%$ dikarenakan aktivitas yang memakan banyak waktu dan gaya hidup yang ingin cepat dan praktis. Perusahaan sadar bahwa peluang ini yang akan menumbuhkan minat konsumen untuk melakukan pembelian ulang setelah mendapatkan kepuasan pada sebuah perusahaan atau merek.

Pengalaman yang dirasakan ketika mengunjungi sebuah laundry juga menjadi pertimbangan konsumen saat ini dalam memilih laundry. Sehingga customer experience perlu menjadi perhatian perusahaan dalam memuaskan konsumennya sehingga dapat memenangkan persaingan. Diharapkan konsumen akan mampu membedakan produk dan jasa yang satu dengan lainnya karena mereka dapat merasakan dan memperoleh pengalaman secara langsung melalui lima pendekatan (sense, feel,think, act, relate), baik sebelum maupun ketika mereka mengkonsumsi sebuah produk ataupun menggunakan sebuah jasa. 
Dalam customer experience, konsumen akan dilibatkan secara emosional dalam setiap kegiatan sehingga customer memiliki pengalaman unik, mengesankan, yang berlangsung pada waktu itu kemudian timbul keinginan untuk kembali menggunakan, lebih dari itu mereka akan membangun merek tersebut secara antusias akan mempromosikan melalui mulut ke mulut pada orang lain. Misalkan saja penataan ruangan yang dengan interior yang menarik disertai dengan pelayan yang ramah, konsumen akan merasa senang dengan perlakuan tersebut, sehingga terciptalah sebuah pengalaman positif dan kepuasan tersendiri selama berada di Dress Up Laundry \& Dry Cleaning Service yang dapat membuat konsumen kembali lagi ke Dress Up Laundry \& Dry Cleaning Service.

Berdasarkan pengalaman peneliti saat melakukan observasi langsung ketempat penelitian yaitu di Dress Up Laundry \& Dry Cleaning Service cabang Benhil, menemukan beberapa pernasalahan dari customer experience Dress Up Laundry yaitu Ruangan Dress Up Laundry \& Dry Cleaning Service beberapa fasilitas tidak berfungsi secara baik diantaranya AC yang kurang nyaman, ruang tunggu yang sempit dan pendukung fasilitas lain yang kurang memadai itu masuk kedalam Sense Experience, dari sisi lain pelayanan yang peneliti rasakanya itu pelayanan yang kurang ramah dan tidak murah senyum itu masuk kedalam Feeling Experience, dan untuk Dress Up Laundry \& Dry Cleaning Service yang bertempat di Benhil keberadaan lokasinya kurang strategis karena terhalang oleh Alfamart dan terhalang oleh para penjual yang berada disekitar Alfamart permasalahan ini masuk kedalam Thingking Experience, dan gaya hidup masyarakat yang bertempat tinggal disekitar wilayah Benhil cenderung tinggi serta ingin serba instan dan praktis dan ini masuk dalam kategori Action Experience, selanjutnya berkaitan dengan Relation Experience adalah tidak adanya tempat untuk kritik dan saran apabila customer tidak puas atau ada keluhan.

Penelitian yang dilakukan oleh Musafir Hasran (2014) hasil penelitian menunjukkan bahwa terdapat pengaruh yang signifikan antara variabel Customer Experience yang terdiridari sense $\left(X_{1}\right)$, feeling $\left(X_{2}\right)$, thinking $\left(X_{3}\right)$, action $\left(X_{4}\right)$, relation $\left(X_{5}\right)$ terhadap pembelian ulang $(\mathrm{Y})$. Dan penelitian yang dilakukan oleh Ika Pratama Kusumawati, Sutopo (2013) menunjukkan bahwa the test result show that customer experience (sense,feeling, thinking,action,relation) have positive and significant affect to repurchase intention is think experience variable.

Namun penelitilainnya dilakukan oleh Livia (2014). Menunjukkan bahwa Sense Experience dan Feeling Experience tidak berpengaruh terhadap minat beli ulang konsumen, sedangkan Thinking Experience, Action Experience dan Relation Experience berpengaruh terhadap minat beli ulang konsumen.

Berdasarkan fenomena dan Riset GAP diatas, maka peneliti tertarik untuk mengetahui lebih lanjut tentang minat beli ulang konsumen khususnya pada Dress Up Laundry \& Dry Cleaning Service yang dituangkan dalam suatu penelitian dengan judul: "Analisis pengaruh customer experience terhadap minat beli ulang konsumen pada dress up laundry \& dry cleaning service cabang benhil Jakarta pusat.

\section{Perumusan Masalah}

1. Apakah Sense Experience berpengaruh terhadap minat beli ulang pada Dress Up Laundry \& Dry Cleaning Service Cabang Benhil?

2. Apakah Feeling Experience berpengaruh positif dan signifikan terhadap minat beli ulang pada Dress Up Laundry \& Dry Cleaning Service Cabang Benhil?

3. Apakah Thinking Experience berpengaruh terhadap minat beli ulang pada Dress Up Laundry \& Dry Cleaning Service Cabang Benhil?

4. Apakah Action Experience berpengaruh terhadap minat beli ulang pada Dress Up Laundry \& Dry Cleaning Service Cabang Benhil?

5. Apakah Relation Experience berpengaruh terhadap minat beli ulang konsumen pada Dress Up Laundry \& Dry Cleaning Service Cabang Benhil? 
6. Apakah Sense Experience, Feeling Experience, Thinking Experience, Action Experience, Relation Experience secara bersama-sama berpengaruh terhadap minat beli ulang pada Dress Up Laundry \& Dry Cleaning Service?

\section{Tujuan dan Kegunaan Penelitian}

1. Tujuan Penelitian

a. Untuk mengetahui pengaruh Sense Experience terhadap minat beli ulang pada Dress Up Laundry \& Dry Cleaning Service Cabang Benhil?

b. Untuk mengetahui pengaruh Feeling Experience terhadap minatbeli ulang pada Dress Up Laundry \& Dry Cleaning Service Cabang Benhil?

c. Untuk mengetahui pengaruh Thinking Experience terhadap minat beli ulang pada Dress Up Laundry \& Dry Cleaning Service Cabang Benhil?

d. Untuk mengetahui pengaruh Action Experience terhadap minat beli ulang pada Dress Up Laundry \& Dry Cleaning Service Cabang Benhil?

e. Untuk mengetahui pengaruh Relation Experience terhadap minat beli ulang pada Dress Up Laundry \& Dry Cleaning Service Cabang Benhil?

f. Untuk mengetahui pengaruh Sense Experience, Feeling Experience, Thinking Experience, Action Experience, Relation Experience secara bersama-sama berpengaruh terhadap minat beli ulang konsumen pada Dress Up Laundry \& Dry Cleaning Service Cabang Benhil?

\section{Manfaat Penelitian}

a. Bagi perusahaan penelitian ini untuk dapat mengetahui faktor yang dapat mempengaruhi minat beli ulang dan menambah informasi kepada perusahaan tentang customer experience.

b. Bagi penelitian ini untuk menambah wawasan dan lebih memahami pengaruh Sense Experience, Feeling Experience, Thinking Experience, Action Experience dan Relation Experience terhadap minat beli ulang.

c. Bagi masyarakat penelitian ini dapat dijadikan bahan referensi untuk memahami faktor yang mempengaruhi minat beli ulang konsumen.

d. Bagi pihak lain penelitian ini diharapkan dapat digunakan sebagai bahan pembanding dan referensi untuk penelitian selanjutnya.

\section{KERANGKA PEMIKIRAN TEORITIS}

\section{Minat beli}

Minat beli ulang yang tinggi mencerminkan tingkat kepuasan yang tinggi dari konsumen ketika memutuskan untuk mengkonsumsi suatu produk. Minat beli ulang ini timbul setelah konsumen mendapatkan kepuasan terhadap suatu produk atau jasa tertentu, sehingga konsumen memiliki keinginan atau minat untuk mengkonsumsi atau melakukan pembelian kembali, dengan adanya minat beli ulang yang terus menerus maka dapat diartikan bahwa konsumen tersebut telah menjadi seorang pelanggan yang loyal terhadap produk atau jasa tertentu

Menurut Nurhayati (2012) minat pembelian ulang adalah keinginan dan tindakan konsumen untuk membeli ulang suatu produk, karena adanya kepuasan yang diterima sesuai yang dinginkan dari suatu produk. Merk yang sudah melekat dalam hati

Menurut Kotler dan Keller (2012:145), ada beberapa faktor utama yang mempengaruhi minat seseorang untuk melakukan pembelian ulang, yaitu:

a. Faktor Psikologis

a) Teori Stimulus Respon

b) Teori Kognitif

c) Teori Gestalt dan Teori Lapangan 
b. Faktor Pribadi

c. Faktor Sosial

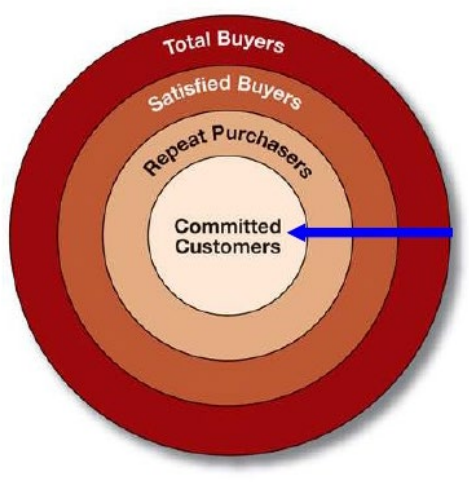

Gambar 2

Creating Committed Customers

Sumber: Hawkins dan Mothersbaugh (2010:640)

Dari gambar 2 menjelaskan bahwa dari seluruh total pembeli terdapat beberapa pembeli yang merasa puas dan tidak puas. Setelah itu dari beberapa pembeli yang merasa puas (statisfied buyers) terdapat juga beberapa yang menginginkan untuk melakukan pembelian kembali atau berulang walaupun tidak menutup kemungkinan bahwa pembeli yang merasa tidak puas juga dapat melakukan pembelian kembali. setelah itu beberapa orang yang telah melakukan pembelian kembali akan menjadi pelanggan tetap.

\section{Customer Experience}

Customer experience cara penciptaan kepuasaan konsumen melalui pengalaman yang bertitik tumpu kepada penghubungan produk akhir dari suatu produk atau pelayanan. Oleh karena itu customer experience bagaimana memahami gaya hidup konsumen dan melebarkan pandangan pemasar dari produk ke proses konsumsi. Evaluasi pengalaman konsumen tergantung pada perbandingan antara harapan konsumen dan kinerja perusahaan

Terdapat beberapa kategori pada customer experience, seperti halnya Robinnete dan Brand (2008) dalam Salim, Catherine dan Andreani (2015:4) yang membagi experience kedalam beberapa kategori, yaitu kategori Customer Experience:

a. Pengalaman dalam produk (Experience in Product)

b. Pengalaman dalam lingkungan (Experience in environment)

c. Pengalaman dalam komunikasi (Experience in Loyalty Communication)

d. Pengalaman berdasarkan pelayanan konsumen dan pertukaran pengalaman sosial (Experience in Customer Service and Social Exchanged Experience)

e. Pengalaman dalam acara (Experience in Events).

\section{Dimensi Customer Experience}

Customer experience tidak dipengaruhi satu unsur/ aspek saja, namun gabungan dari banyak aspek, sehingga komponen- komponen tersebut dapat dikelompokkan ke dalam 5 dimensi customer experience sebagai bentuk aplikasi pendekatan yang dapat dilakukan perusahaan untuk memberikan pengalaman kepada konsumennya. Menurut Smith (1999) dalam Salim, Catherine dan Andreani (2015:326) dimensi dari customer experience adalah sebagai berikut 
a. Indera (Sense)

b. Rasa (Feel)

c. Pengalaman (Think)

d. Gaya Hidup (Act)

e. Relate

\section{METODE PENELITIAN \\ Desain Penelitian}

Desain penelitian ini menggunakan penelitian kausal. Penelitian kausal merupakan penelitian untuk mengetahui pengaruh antara satu variabel bebas (independent variable) terhadap variabel terikat (dependent variable). Desain penelitian yang pertama yaitu untuk mengetahui apakah variabel Sense Experience berpengaruhterhadap minat beli ulang konsumen. Desain penelitian kedua yaitu untuk mengetahui Feeling Experience berpengaruhterhadap minat beli ulang konsumen. Desain penelitian ketiga yaitu untuk mengetahui Thinking Experience berpengaruhterhadap minat beli ulang konsumen. . Desain penelitian keempat yaitu untuk mengetahui Action Experience berpengaruhterhadap minat beli ulang konsumen. Desain penelitian kelima yaitu untuk mengetahui Relation Experience berpengaruh terhadap minat beli ulang konsumen.

\section{Hipotesis Statistik}

Berdasarkan pada landasan teori dan kerangka pemikiran diatas, Hipotesis Statistika yang diajukan dalam penelitian ini adalah sebagai berikut:

$\mathrm{H}_{\mathrm{o} 1}$ : Sense experience tidak berpengaruh terhadap minat beli ulang konsumen pada Dress UpLaundry\& Dry Cleaning Service

$\mathrm{H}_{\mathrm{a} 1}$ : Sense experience berpengaruh terhadap minat beli ulang konsumen pada Dress UpLaundry\& Dry Cleaning Service

$\mathrm{H}_{\mathrm{o} 2}$ : $\quad$ Feeling experience tidak berpengaruh terhadap minat beli ulang konsumen pada Dress UpLaundry\& Dry Cleaning Service

$\mathrm{H}_{\mathrm{a} 2}$ : $\quad$ Feeling experience berpengaruh terhadap minat beli ulang konsumen pada Dress UpLaundry\& Dry Cleaning Service

$\mathrm{H}_{03}$ : $\quad$ Thinking experience tidak berpengaruh terhadap minat beli ulang konsumen padaDress UpLaundry\& Dry Cleaning Service

$\mathrm{H}_{\mathrm{a} 3}$ : Thinking experience berpengaruh terhadap minat beli ulangkonsumen padaDressUpLaundry\& Dry Cleaning Service

$\mathrm{H}_{04} \quad$ Action experience tidak berpengaruh terhadap minat beli ulang konsumen pada Dress UpLaundry\& Dry Cleaning Service

$\mathrm{H}_{\mathrm{a} 4}$ : Action experience berpengaruh terhadap minat beli ulang pada konsumen DressUpLaundry\& Dry Cleaning Service

$\mathrm{H}_{05}$ : Relation experience tidak berpengaruh terhadap minat beli ulang konsumen pada Dress UpLaundry\& Dry Cleaning Service

$\mathrm{H}_{\mathrm{a} 5}$ : Relation experience berpengaruh terhadap minat beli ulang konsumen pada Dress UpLaundry\& Dry Cleaning Service

$\mathrm{H}_{\mathrm{o6}}$ : Sense experience, Feeling Experience, Thinking Experience, Action Experience, Relation Experience secara bersama-sama tidak berpengaruh terhadap minat beliulangkonsumen pada Dress UpLaundry\& Dry Cleaning Service.

$\mathrm{H}_{\mathrm{a} 6}$ : Sense experience, Feeling Experience, Thinking Experience, Action Experience, Relation Experience secara bersama-sama berpengaruh terhadap minat beli ulangkonsumen pada Dress UpLaundry\& Dry Cleaning Service. 


\section{Variabel Dan Skala Pengukuran Variabel Penelitian}

1. Variabel Independen

Menurut Sugiyono (2016:39) variabel ini sering disebut sebagai variabel stumulus, predictor, antecedent. Dalam bahasa Indonesia sering disebut sebagai variabel bebas.Variabel bebas adalah merupakan variabel yang mempengaruhi atau yang menjadi sebab perubahannya atau timbulnya variabel dependen (terikat) dalam penelitian ini variabel independen.

a. Sense Experience $\left(\mathrm{X}_{1}\right)$

Sense adalah indra yang dimiliki oleh manusia sebagai alat untuk merasakan produk atau jasa yang ditawarkan (Schimitt dalam Kustini, 2007). Sense Experience adalah usaha penciptaan suatu pengalaman yang berkaitan dengan panca indra melalui penglihatan, suara, sentuhan, rasa, dan bau.

b. Feeling Experience $\left(\mathrm{X}_{2}\right)$

Menurut Schimmt (dalam Kustini, 2007) Feeling Experience dapat ditampilkan melalui ide, kesenangan, dan reputasi akan pelayanan pelanggan.

c. Thinking Experience $\left(\mathrm{X}_{3}\right)$

Menurut Schimmt (dalam Kustini, 2007) Thinking Experience adalah meliputi creative dan cognitive, maksud dari creative dan cognitive adalah bahwa umtuk pemasaran thinking menuntut kecerdasan dengan tujuan menciptakan pengalaman kognitif dan pemecahan masalah dengan melibatkan pelanggan secara kreatif.

d. Action Experience $\left(\mathrm{X}_{4}\right)$

Action Experience menurut Schimmt (dikutip Kustini, 2007) adalah didesain untuk menciptakan pengalaman pelanggan yang berhubungan dengan tubuh secara fisik, pada perilaku dan gaya hidup jangka panjang serta pengalaman-pengalaman yang terjadi sebagai hasil dari interaksi dengan orang lain.

e. Relation Experience $\left(\mathrm{X}_{6}\right)$

Menurut Schimmt (dikutip Kustini, 2007) Relation Experience secara umum menunjukkan adanya hubungan dengan orang lain, kelompok sosial lain (seperti pekerjaan, gaya hidup) atau identitas sosial yang lebih luas. Customer experienceDress Up Laundry\& Dry Cleaning Service berpengaruh terhadap minat beli ulang.

2. Variabel dependen

Menurut Sugiyono (2016:39) variabel ini sering disebut variabel output, kriteria, konsekuen. Dalam bahasa Indonesia sering disebut sebagai variabel terikat.Variabel terikat merupakan variabel yang dipengaruhi atau yang menjadi akibat, karena adanya variabel bebas. Dalam penelitian ini variabel dependen:

a. Minat Beli Ulang (Y)

Minat beli ulang menurut simamora (2004) adalah keinginan dan tindakan konsumen untuk membeli ulang suatu produk, karena adanya kepuasan yang diterima sesuai yang dinginkan dari suatu produk.

a) Sense Experience berpengaruh terhadap minat beli ulang konsumen

b) Feeling Experience berpengaruh terhadap minat beli ulang konsumen

c) Thinking Experience berpengaruh terhadap minat beli ulang konsumen

d) Action Experience berpengaruh terhadap minat beli ulang konsumen

e) Relation Experience berpengaruh terhadap minat beli ulang konsumen

f) Sense Experience, Feeling Experience, Thinking Experience, Action Experience, Relation Experience secara bersama-sama berpengaruh terhadap minat beli ulang konsumen

\section{Jenis Data}

Sumber data dalam penelitian ini adalah data primer dan data sekunder. Berikut sumber data dalam penelitian sebagai berikut :

1. Data primer 
Menurut Sugiyono (2016: 225) data primer adalah sumber data yang langsung memberikan data kepada pengumpul data. Data primer pada penelitian ini yaitu yang pertama kali dicatat dan dikumpulkan oleh peneliti.

\section{Data sekunder}

Menurut Sugiyono (2016: 225) data sekunder merupakan sumber yang tidak langsung memberikan data kepada pengumpul data, misalnya lewat orang lain, atau dokumen. Data ini juga diperoleh melalui data-data yang dikumpulkan dari berbagai studi pustaka seperti textbooks, jurnal, maupun artikel referensi dimedia elektronik.

\section{Metode Pengumpulan Data}

Menurut Sugiyono (2016:224) berikut merupakan teknik pengumpulan data antara lain:

1. Kuesioner/angket

Kuesioner merupakan teknik pengumpulan data yang dilakukan dengan cara memberi seperangkat pertanyaan atau pernyataan tertulis kepada responden untuk dijawabnya. Pada penelitian ini kuesioner digunakan untuk mengetahui minat beli ulang pada pada Dress Up Laundry \& Dry Cleaning Laundry. Pernyataan dan pertanyaan yang ada didalam kuesioner akan diukur dengan menggunakan tipe skala Likert.

2. Observasi

Observasi merupakan suatu proses yang kompleks, suatu proses yang tersusun dari berbagai proses biologis dan psikologis. Dua diantara yang terpenting adalah proses-proses pengamatan dan ingatan.

\section{Populasi dan Sampel Penelitian}

\section{Populasi}

Menurut Sugiyono (2016:80) populasi adalah wilayah generalisasi yang terdiri atas objek/subyek yang mempunyai kualitas dan karakteristik tertentu yang ditetapkan oleh peneliti untuk dipelajari dan kemudian ditarik kesimpulanya. Populasi merupakan obyek atau subyek yang berada pada wilayah yang memenuhi syarat tertentu terkait dengan permasalahan penelitian.

Populasi dalam penelitian ini adalah customer Dress Up Laundry \& Dry Cleaning Service berjumlah 1.807 orang.

\section{Sampel}

Menurut Sugiyono (2016:81) sampel adalah bagian dari jumlah dan karakteristik yang dimiliki oleh populasi tersebut. Bila populasi besar, dan peneliti tidak mungkin mempelajari semua yang ada pada populasi, misalnya karena keterbatasan dana, tenaga dan waktu, maka peneliti dapat menggunakan sampel yang diambil dari populasi itu.

\section{Teknik Pengumpulan Sampel}

Menurut Sugiyono (2016:82) probability sampling adalah teknik pengambilan sampel yang memberikan peluang yang sama bagi setiap unsur (anggota) populasi untuk dipilih menjadi anggota sampel. Teknik sampling yang digunakan dalam penelitian ini adalah Simple Random Sampling.

Menurut Sugiyono (2016:82) dikatakan simple (sederhana) karena pengambilan anggota sampel dari populasi dilakukan secara acak tanpa memperhatikan strata yang ada dalam populasi itu Untuk menentukan jumlah sampel, perlu menggunakan rumus Slovin sebagai berikut:

$$
n=\frac{N}{1+N e^{2}}
$$

Keterangan : 
$\mathrm{n} \quad=$ Jumlah elemen/anggota sampel

$\mathrm{N}=$ Jumlah elemen/anggota populasi

e $\quad=$ Error level (tingkat kesalahan) ditetapkan 10\% dengan tingkat kepercayaan $90 \%$;

Tabel 3.2

Total Customer Dress Up Laundry \& Dry Cleaning Service

\begin{tabular}{|l|c|}
\hline \multicolumn{1}{|c|}{ Bulan } & Total Customer \\
\hline Januari 2016 & 137 \\
\hline Februari 2016 & 118 \\
\hline Maret 2016 & 120 \\
\hline April 2016 & 180 \\
\hline Mei 2016 & 195 \\
\hline Juni 2016 & 153 \\
\hline Juli 2016 & 160 \\
\hline Agustus 2016 & 153 \\
\hline September 2016 & 135 \\
\hline Oktober 2016 & 156 \\
\hline November 2016 & 153 \\
\hline Desember 2016 & 147 \\
\hline Total & 1.807 \\
\hline
\end{tabular}

Sumber: perusahaan, 2017

Populasi yang didapatkan dari Dress Up Laundry \& Dry Cleaning Service peiode Januari sampai Desember 2016 adalah sebanyak 1.807 orang. Maka dapat dihitung sampel dengan tingkat kesalahan yang ditetapkan yaitu $10 \%$, sebagai berikut :

$$
\begin{aligned}
& n=\frac{N}{1+N e^{2}} \\
& n=\frac{1807}{1+1807(0,1)^{2}} \\
& \mathrm{n}=94.75
\end{aligned}
$$

\section{HASIL DAN PEMBAHASAN}

\section{Pengaruh Sense Terhadap Minat Beli Ulang}

Berdasarkan hasil perhitungan dapat disimpulkan sense $\left(\mathrm{X}_{1}\right)$ mempunyai $\mathrm{t}$ hitung $>\mathrm{t}$ tabel $(2,853>1,986)$ dan nilai signifikansi $0,005<0,05$ maka Ho ditolak Ha diterima artinya sense berpengaruh signifikan terhadap minat beli ulang. Hubungan sense terhadap minat beli ulang adalah positif atau searah yang sedang. Hal ini sesuai penelitian Livia yangberjudul Analisa Pengaruh Customer Experience Terhadap Minat Beli Konsumen Di Sushi Tei Restaurant Surabaya hasil penelitian sense berpengaruh terhadap minat beli ulang. Karena sensory experience merupakan usaha untuk menciptakan pengalaman yang berkaitan dengan panca indra, meliputi penglihatan, suara, bau, rasa dan sentuhan. 


\section{Pengaruh Feel Terhadap Minat Beli Ulang}

Berdasarkan hasil perhitungan dapat disimpulkan Feel $\left(\mathrm{X}_{2}\right)$ mempunyai $\mathrm{t}$ hitung $>\mathrm{t}$ tabel $(2,084>1,986)$ dan nilai signifikansi $0,040<0,05$ maka Ho ditolak Ha diterima artinya feel berpengaruh signifikan terhadap minat beli ulang. Hubungan feel terhadap minat beli ulang adalah positif atau searah yang kuat. Hal ini sesuai penelitian Amir Nasermoadeli, Kwek Choon Ling dan Farshad Maghnati yang berjudul Evaluating the Impacts of Customer Experience on Purchase Intention hasil penelitian feel berpengaruh terhadap minat beli ulang. Karena Feel merupakan perasaan emosi yang muncul dari dalam hati secara positif dan perasaan gembira yang terjadi pada saat mengkonsumsi. Unsur feel meliputi tentang suasana hati dan perasaan atau emosi positif. Pengalaman yang affective adalah pengalaman yang bertingkat perasaan-perasaan (feelings) yang memiliki beragam intensitas, mulai dari mood tingkat ringan, baik yang positif ataupun negatif, sampai emosi yang kuat.

\section{Pengaruh Think Terhadap Minat Beli Ulang}

Berdasarkan hasil perhitungan dapat disimpulkan Think $\left(X_{3}\right)$ mempunyai $\mathrm{t}$ hitung $>\mathrm{t}$ tabel $(3,554>1,986)$ dan nilai signifikansi $0,001<0,05$ maka Ho ditolak Ha diterima artinya think berpengaruh signifikan terhadap minat beli ulang. Hubungan think terhadap minat beli ulang adalah positif atau searah yang sangat kuat. Hal ini sesuai penelitian Ika Pratama Kusumawati dan Sutopo yang berjudul Analisis Pengaruh Customer Experience Terhadap Minat Beli Ulang (Studi kasus pada konsumen restoran The House of Raminten Yogyakarta) hasil penelitian think berpengaruh terhadap minat beli ulang. Karena thinking experience dapat memberikan pengaruh terhadap minat beli ulang konsumen sehingga konsumen mau berpikir positif saat mengkonsumsi produk atau jasa.

\section{Pengaruh Act Terhadap Minat Beli Ulang}

Berdasarkan hasil perhitungan dapat disimpulkanAct $\left(X_{4}\right)$ mempunyai $\mathrm{t}$ hitung $>\mathrm{t}$ tabel $(2,240>1,986)$ dan nilai signifikansi $0,028<0,05$ maka Ho ditolak Ha diterima artinya act berpengaruh signifikan terhadap minat beli ulang. Hubungan act terhadap minat beli ulang positif atau searah yang kuat. Hal ini sesuai penelitian Livia yang berjudul Analisa Pengaruh Customer Experience Terhadap Minat Beli Konsumen Di Sushi Tei Restaurant Surabaya hasil penelitian act berpengaruh terhadap minat beli ulang. Karena social exprience atau sense experience bertujuan untuk menghubungkan individu kepada orang lain, kepada suatu kelompok sosial (kelompok profesi, kelompok etnis, kelompok gaya hidup, dan lain-lain), maupun kepada suatu entitas sosial yang lebih abstrak seperti suatu negara, masyarakat, atau budaya tertentu yang direfleksikan dalam suatu brand. Melalui social experience, konsumen menjadi terhubung dengan suatu lingkungan sosial yang lebih luas sehingga menumbuhkan brand relation dan brand communities.

\section{Pengaruh Relate Terhadap Minat Beli Ulang}

Berdasarkan hasil perhitungan dapat disimpulkan Relate $\left(X_{5}\right)$ mempunyai $\mathrm{t}$ hitung $>\mathrm{t}$ tabel $(2,611>1,986)$ dan nilai signifikansi $0,011<0,05$ maka Ho ditolak Ha diterima artinya relate berpengaruh signifikan terhadap minat beli ulang. Hubungan relate minat beli ulang positif atau searah yang kuat. Hal ini sesuai penelitian Muhammad Hafiz Sayuti dan Citra Kusuma Dewi, yang berjudul Analisis Pengaruh Customer Experience Terhadap Minat Beli Ulang Konsumen Pada Kafe Nom Nom Eatery Bandung hasil penelitian relate berpengaruh terhadap minat beli ulang. Karena pada umumnya relate experience menunjukkan hubungan dengan orang lain, kelompok sosial (misalnya pekerjaan, gaya hidup) atau komunitas sosial yang lebih luas dan abstrak (misalnya Negara, masyarakat, budaya). Tujuan dari relate experience adalah menghubungkan konsumen tersebut dengan budaya dan lingkungan sosial yang dicerminkan oleh merek suatu produk. 


\section{Pengaruh Sense, Feel, Think, Act, Relate Terhadap Minat Beli Ulang}

Berdasarkan hasil pengolahan data dapat disimpulkan Nilai $\mathrm{F}$ hitung $>\mathrm{F}$ tabel $(58.466>$ 2,471 ) dan nilai probabilitas (signifikan) adalah sebesar $0,000<0,05$ maka Ho ditolak dan Ha diterima. Dapat disimpulkan sense, feel, think, act, relate, secara bersama-sama berpengaruh signifikan terhadap minat beli ulang sebesar $75,3 \%$ dan sisanya $24,7 \%$ dipengaruhi variabel lain yang tidak dijelaskan dalam penelitian ini.

\section{KESIMPULAN DAN SARAN \\ Kesimpulan}

Dari hasil analisis penelitian yang dilakukan mengenai Customer Experience terhadap minat beli ulang konsumen, terdapat simpulan yang dapat ditarik dari penelitian ini sebagai berikut:

1. Sense Experience pada CV. Dress Up Laundry \& Dry Cleaning Service berpengaruh positif dan signifikan terhadap minat beli ulang konsumen.

2. Feeling Experience pada CV. Dress Up Laundry \& Dry Cleaning Service berpengaruh positif dan signifikan terhadap minat beli ulang konsumen.

3. Thinking Experience pada CV. Dress Up Laundry \& Dry Cleaning Service berpengaruh positif dan signifikan terhadap minat beli ulang konsumen.

4. Act Experience pada CV. Dress Up Laundry \& Dry Cleaning Service berpengaruh positif dan signifikan terhadap minat beli ulang konsumen.

5. Relate Experience pada CV. Dress Up Laundry \& Dry Cleaning Service berpengaruh positif dan signifikan terhadap minat beli ulang konsumen.

6. Sense Experience, Feeling Experience, Thinking Experience, Act Experience, Relate Experience pada CV. Dress Up Laundry \& Dry Cleaning Service secara simultan berpengaruh positif dan signifikan terhadap minat beli ulang konsumen sebesar 75,3\% dan sisanya. $24,7 \%$ dipengaruhi oleh varibel lain yang tidak dijelaskan dalam penelitian ini.

\section{Saran}

Adapun saran untuk CV. Dress Up Laundry \& Dry Cleaning Service antara lain:

1. Berdasarkan hasil kuesioner dan pembahasan mengenai variabel sense experience ditemukan bahwa pernyataan nomor 6 dengan pernyataan "setelah di laundry pakaian menjadi bersih" memiliki nilai mean terendah 3,86. Dalam hal ini perusahaan harus memiliki Standar Operasional perusahaan (SOP) mengenai pakaian bersih dan memberikan pelatihan kepada karyawan mengenai standar baju bersih.

2. Berdasarkan hasil kuesioner dan pembahasan mengenai variabel Feel experience ditemukan bahwa pernyataan nomor 4 dengan pernyataan "Pelayanan yang ramah (Assurance)" memiliki nilai mean terendah 3,34. Diharapkan perusahaan memberikan pelatihan pelayanan prima kepada karyawan.

3. Berdasarkan hasil kuesioner dan pembahasan mengenai variabel Think experience ditemukan bahwa pernyataan nomor 7 dengan pernyataan "Lokasi mudah dijangkau" memiliki nilai mean terendah 3,31. Perusahaan perlu membuat spanduk besar agar lokasinya terlihat.

4. Berdasarkan hasil kuesioner dan pembahasan mengenai variabel Act experience ditemukan bahwa pernyataan nomor 4 dengan pernyataan "Customer lebih mengutamakan kualitas yang tinggi" memiliki nilai mean terendah 3,64. Perusahaan diharapkan meningkatkan kualitas hasil laundry.

5. Berdasarkan hasil kuesioner dan pembahasan mengenai variabel Relate experience ditemukan bahwa pernyataan nomor 4 dengan pernyataan "Karyawan dapat berkomunikasi dengan baik" memiliki nilai mean terendah 3,62. Dalam hal ini perusahaan harus memberikan pelatihan public speaking.

6. Berdasarkan hasil kuesioner dan pembahasan mengenai variabel Minat beli ulang ditemukan bahwa pernyataan nomor 5 dengan pernyataan "Saya mengajak Keluarga atau teman 
menggunakan jasa Dress Up Laundry \& Dry Cleaning Service” memiliki nilai mean terendah 3,27 . Dalam hal ini perusahaan harus meningkatkan promosi agar customer kembali lagi.

\section{DAFTAR PUSTAKA}

Ali, Hasan. 2013. Marketing dan Kasus-KasusPilihan. Yogyakarta: CAPS (Center For Academic Publishing Service).

Alma, Buchari. 2014. Manajemen Pemasaran dan Pemasaran Jasa. Bandung: Alfabeta,

Hawkins, D.I., dan Mothersbaugh, D.L. 2010. Consumer Behavior: Building Marketing Strategy.11th edition. McGraw-Hill, Irwin

Kotler, Philip dan Gary Armstrong. 2012. Prinsip-prinsip Pemasaran Edisi 13 Jilidl. Jakarta: Erlangga.

Kotler, Philip dan Kevin Lane Keller. 2012. Marketing Management 13. New Jersey: Pearson Prentice Hall, Inc

Kustini. 2007. Penerapan Experiential Marketing. Jurnal Riset Ekonomi Bisnis.

Levy, Michael \& Weitz, Barton A., 2012. Retailing Management. New York, America: McGrawHill/ Irwin.

Lupiyoadi, Rambat. 2013. Manajemen Pemasaran Jasa, Jakarta: Salemba EmpatPramudita, Yoana dan Japarianto, Edwin.

2013. Analisis Pengaruh Customer Experience dan Customer Value Terhadap Customer Satisfaction di De Kasteel Resto Surabaya. Jurusan Manajemen Pemasaran. Surabaya.

Priyatno, Duwi. 2014. SPSS 22 Pengolah Data Terpraktis. Andi.Yogyakarta.

Sugiyono. 2016. Metode Penelitian Kuantitatif, Kualitatif $R \&$ D Cetakan Ke-23. Bandung: Alfabeta

Tjiptono, Fandy. 2014. Pemasaran Jasa. Jakarta: Gramedia.

\section{Jurnal}

Amir Nasermoadeli, K. C. (2013). Evaluating the Impacts of Customer Experience on Purchase Intention. International Journal of of Business and Management; Vol. 8, No.6, 128-138.

Ayu Sari Prastyaningsih, I. S. (2016). Pengaruh Customer Experience Terhadap Repuchase Intention . Jurnal Administrasi Bisnis (JAB) Vol. 16 No.1, 1-8.

Fredrick Alfian, P. H. (2016). Analisis Pengaruh Customer Experience Terhadap

Minat Beli Ulang Pada Wiki Koffie Bandung. e-Procedding of Management : Vol.3, No.1, 647-654.

Livia. (2014). Analisa Pengaruh Customer Experience Terhadap Minat Beli Konsumen Di Sushi Tei Restaurant Surabaya. Jurnal Hospitality dan Manajemen Jasa Vol 2, No 2 , 58-75.

Muhammad Hafiz Sayuti, C. K. (2015). Analisis Pengaruh Customer Experience Terhadap Minat Beli Ulang Konsumen Pada Kafe Nom Nom Eatery Bandung. e-Proceeding of Mnagement : Vol.2, No.2, 1932-1940.

Sutopo, I. P. (2013). Analisis Pengaruh Customer Experience Terhadap Minat Beli Ulang. Diponegoro Journal Of Management, 1-9. 
